\title{
Article
}

\section{Association of the calpain-10 gene with microvascular function}

\author{
A. C. Shore ${ }^{1}$, J. C. Evans ${ }^{1}$, T. M. Frayling ${ }^{1}$, P. M. Clark ${ }^{2}$, B. C. Lee ${ }^{1}$, Y. Horikawa ${ }^{3}$, A. T. Hattersley ${ }^{1}$, \\ J. E. Tooke ${ }^{1}$ \\ ${ }^{1}$ Peninsula Medical School and University of Exeter, Exeter, UK \\ ${ }^{2}$ Regional Endocrine Laboratory, University Hospital Birmingham NHS Trust, Birmingham, UK \\ ${ }^{3}$ Howard Hughes Medical Institute, and Departments of Biochemistry and Molecular Biology, The University of Chicago, \\ Chicago, Illinois, USA
}

\section{Abstract}

Aims/hypothesis. Genotype could influence vascular function. In some populations, Calpain 10 gene polymorphisms increase susceptibility to diabetes or insulin resistance. Alterations in microvascular function could contribute to insulin resistance. This study investigated whether polymorphisms in the Calpain-10 gene influence microvascular function.

Methods. Skin maximum microvascular hyperaemia to local heating on the dorsum of the foot $(30 \mathrm{~min}$ at $43^{\circ} \mathrm{C}$ ) was measured by Laser Doppler Fluximetry in 37 healthy volunteers. All were normoglycaemic according to World Health Organisation criteria, normotensive and not on any medication.

Four polymorphisms in the calpain-10 gene were typed: SNP-44, SNP-43, SNP-19, SNP-63. The SNP common to all the described high risk haplotypes is the G-allele at SNP-43. This intron 3 polymorphism appears to influence gene expression. Microvascular function was examined in relation to polymorphisms at this site alone as well as the effects of the known extended high risk haplotypes using the SNP's above.

Results. Maximum microvascular hyperaemia was increased in the 21 subjects with $G / G$ genotypes at SNP-43 compared to the combined group of subjects (G/A genotype at SNP-43 $(n=12)+A / A$ genotype at SNP-43 $(n=4)$ ), and the minimum microvascular resistance was reduced 49.4 (39.6-94.2) vs 67.5 (39.1-107.3) $\mathrm{mmHg} / \mathrm{V}, p=0.007)$. Haplotype analysis of the hyperaemic response revealed no significant differences between haplotypes. The two groups did not differ in terms of anthropometric measures, blood pressure, insulin resistance or glucose.

Conclusions/interpretation. The polymorphism that confers susceptibility to Type II (non-insulin-dependent) diabetes mellitus in some populations is associated in United Kingdom Caucasians with enhanced microvascular function in the presence of normoglycaemia. [Diabetologia (2002) 45:899-904]

Keywords Calpain 10, microvascular function, skin hyperaemia, genotype, normoglycaemia.
Received: 12 November 2001 / Revised: 11 February 2002

Published online: 15 May 2002

C) Springer-Verlag 2002

Corresponding author: Dr. A. C. Shore, Institute of Biomedical and Clinical Science, Peninsula Medical School, Barrack Road, Exeter, Deron EX2 5AX, UK, e-mail: A.C.Shore@exeter.ac.uk Abbreviations: MODY3, Maturity onset Diabetes of the Young (hepatocyte nuclear factor-1 $\alpha$ ); ACE, angiotensin I converting enzyme; BP, Blood pressure; WHO, World Health Organisation; MMH, maximum microvascular hyperaemia; MVR, minimum microvascular resistance; HOMA, homeostasis model Assessment; I/D, insertion/deletion; G/G, homozygous for $\mathrm{G}$ allele at SNP-43; G/A, heterozygous for C/A alleles at SNP-43; A/A, homozygous for A allele at SNP-43; CAPN10, calpain-10 gene; SNP, sodium nitroprusside; $\mathrm{D} / \mathrm{D}$, deletion/deletion; eNOS, endothelial nitric oxide synthase
Normal microvascular function is vital for tissue health. The microvasculature is the site of nutrient and waste product exchange and it plays an important role in the maintenance of tissue fluid economy and immune responses.

In patients with both Type I (insulin-dependent) and Type II (non-insulin-dependent) diabetes mellitus, microvascular complications are a major cause of morbidity and are accompanied by marked microvascular dysfunction $[1,2,3]$. Even before clinical microvascular complications are evident, abnormalities of the responsiveness of the microvasculature have been described, for example the hyperaemic response is im- 
paired in prepubertal children with Type I diabetes [4, 5]. Furthermore impaired microvascular function could even precede the development of diabetes $[6,7$, 8] leading to the suggestion that there could be an intrinsic microvascular abnormality in those destined to develop diabetes [9].

Although many studies have examined relations between various genotypes and the risk of cardiovascular disease or macrovascular function, few have examined the effects of genotype on in vivo resistance vessel or microvascular function. In patients with the type 3 form of maturity-onset diabetes of the young (MODY3) which results from mutations in the betacell transcription factor hepatocyte nuclear factor- $1 \alpha$, we described an impaired skin microvascular hyperaemic response with characteristics similar to those previously seen in patients with Type I diabetes [10]. Several groups have investigated the vascular effects of insertion/deletion (I/D) polymorphisms of the angiotensin I converting enzyme (ACE) gene with conflicting results. In healthy individuals, forearm resistance vessel vasodilatory function might be unaffected or blunted in those with the D-allele [11, 12]. However, others report an impaired forearm vasodilatory response only in subjects with the D-allele in combination with the angiotensinogen T174M genotype [13]. Individuals with the ACE D/D genotype display an enhanced vasoconstrictor response to angiotension I [14] although the vasoconstrictor response to noradrenaline is unaltered [12]. In healthy individuals the beta 2 adrenoreceptor genotype is also associated with altered forearm vascular responses to catecholamines $[15,16]$. A lack of biological effects of the endothelial nitric oxide synthase (eNOS) Glu298Asp polymorphism on forearm vasculature has been described [17].

Variation in the calpain-10 gene (CAPN10) has been associated with Type II diabetes in the Mexican American population of Starr County, Texas, and in some Northern Europeans including the Finnish population from the Botnia region, Germans and British $[18,19]$. These studies suggest that risk is not conferred by a single DNA polymorphism but rather there are multiple risk alleles of CAPN10. The single nucleotide polymorphism (SNP)-43 (CAPN10-g.4852G/A) is associated with increased risk in Mexican Americans and Finns/Botnians with odds ratios (OR, 95\%CI) of $1.54(0.88-2.14)$ and 1.84 (1.18-2.88), respectively. Inheritance of a haplotype combination defined by SNP-43, SNP-19 (CAPN10-g.7920indel32 bp) and SNP-63 (CAPN10-g.16378C/T) is associated with a threefold risk in Mexican Americans and in a combined Finnish and German group. In the UK, the association with SNP-43 is less clear; there was no association with Type II diabetes [19] but in a non-diabetic cohort $G / G$ genotype at SNP-43 was associated with higher blood glucose concentrations. An adjacent SNP, SNP-44 (CAPN10-g.4841T/C) shows linkage and association with Type II diabetes in a group of UK parent-offspring trios (OR=1.59 (1.15-2.20) [19]. SNPs 43 and 44 have been shown to alter transcription of Calpain 10 in vitro [18]. In addition SNP-43 is associated with reduced skeletal muscle calpain-10 mRNA content and increased measures of insulin resistance in normal glucose tolerant Pima Indians although it is not associated with Type II diabetes in itself in this population [20].

The molecular mechanism(s) by which calpain-10 affects insulin action and/or insulin secretion and hence insulin resistance or risk of Type II diabetes are unknown. Calpain-10 mRNA is found in all fetal and adult tissues tested [18]. Calpains have been implicated in the regulation of adipocyte differentiation [21] and insulin-induced down regulation of insulin receptor substrate 1 [22] and could affect insulin action and diabetes risk through effects on these processes. An alternative explanation might be that Calpain-10 has an affect on microvascular function.

Microvascular function is abnormal not only in individuals with diabetes, but also in prediabetic hyperglycaemic subjects as well as in those with increased susceptibility to diabetes [7, 23, 24]. Indeed redistribution of blood flow from nutritive to non-nutritive capillaries contributes to insulin resistance in animals $[25,26]$ and skin capillary recruitment, endothelial responses and maximum hyperaemia correlate with insulin resistance in man suggesting a key role for the microcirculation in the determination of insulin resistance [27, 28, 23]. Calpains have been implicated in processes that could potentially affect vascular function including platelet activation, integrin-mediated cell adhesion, signalling and cytoskeletal associations, and the protein kinase $\mathrm{C}$ pathway [29, 30, 31, 32]. Calpain-10 could be involved in regulating these processes and thus provide a link between microvascular function, insulin resistance and diabetes risk. We tested this hypothesis by assessing the skin microvascular hyperaemic response in a group of normal subjects with different $C A P N 10$ genotypes.

\section{Subjects and methods}

Subjects. Thirty seven healthy Caucasian subjects were recruited by advertisement from the local population. Their age ranged from 21 to 55 years, mean 38.5 years, 27 were women. The phase of the menstrual cycle was not standardised. All were normotensive (blood pressure (BP) $\leq 138 / 95 \mathrm{mmHg}$ ) with BMI ranging from 16.6 to $38.2 \mathrm{Kg} / \mathrm{m}^{-2}$. None were taking any medication. All subjects underwent a $2-\mathrm{h} 75 \mathrm{~g}$ oral glucose tolerance test and were normoglycaemic according to WHO criteria. All subjects gave written informed consent to take part in this study which was approved by the Local Medical Research Ethics Committee.

Vascular measurements. Maximum microvascular hyperaemia was determined following a maximum heating stimulus as de- 
Table 1. Clinical features of study groups based on SNP-43 genotype

\begin{tabular}{|c|c|c|c|}
\hline & G/G (Group 1) & $\mathrm{G} / \mathrm{A}+\mathrm{A} / \mathrm{A}($ Group 2) & $p$ \\
\hline Age (years) & $39.0(25.1-54.7)$ & $39.0(21.0-49.0)$ & 0.964 \\
\hline Smokers & 5 & 2 & \\
\hline Weight (kg) & $71.3(48.2-109.3)$ & $71.9(46.2-98.2)$ & 0.617 \\
\hline $\operatorname{BMI}\left(\mathrm{kg} / \mathrm{m}^{2}\right)$ & $24.3(18.5-38.0)$ & $25.5(16.6-37.8)$ & 0.617 \\
\hline Waist to hip ratio & $0.79(0.66-1.27)$ & $0.82(0.70-1.08)$ & 0.962 \\
\hline Fasting plasma glucose $(\mathrm{mmol} / \mathrm{l})$ & $4.4(3.3-5.0)$ & $4.6(3.7-4.9)$ & 0.055 \\
\hline $2 \mathrm{~h}$ plasma glucose $(\mathrm{mmol} / \mathrm{l})$ & $4.6(3.8-7.2)$ & $5.1(3.6-7.4)$ & 0.220 \\
\hline HOMA (\% normal) & $86.1(23.8-943.4)$ & $74.4(50.2-495.7)$ & 0.400 \\
\hline Insulinogenic index $\left(\times 10^{9}\right)$ & $139(57.9-432.2)$ & $124.3(1.49-276.3)$ & 0.622 \\
\hline Plasma Cholesterol (mmol/l) & $4.95(2.66-6.97)$ & $5.05(2.90-6.10)$ & 0.671 \\
\hline
\end{tabular}

scribed previously in detail [23]. Briefly a thermostatically controlled brass heating element set at $43^{\circ} \mathrm{C}$ is used to heat the skin on the dorsum of the foot for a minimum of $30 \mathrm{~min}$ which achieves maximum microvascular dilatation. The red cell flux, a measure of microvascular blood flow, through the microvessels underlying the heating element, is then measured using a laser Doppler flowmeter (model PF3B, Perimed, Upsala, Sweden). The probe is placed eccentrically through the heating element which can be rotated in its holder so that eight spaced measurements of flux values can be made and a mean value calculated. Employed in this way highly reproducible estimations of maximum microvascular hyperaemia $(\mathrm{MMH})$ could be derived (coefficient of variation $5.6 \%$ for subjects measured on multiple occasions over a 6-month period).

Minimum microvascular resistance (MVR) was calculated to correct for differences in blood pressure by dividing mean blood pressure by the value for maximum microvascular hyperaemia. Brachial artery blood pressure was measured as the mean of three resting values using an automated device (Dinamap, Critikon, Tampa, Fla., USA).

Metabolic assessments. An index of insulin sensitivity was calculated by the HOMA model using two fasting insulin and glucose measurements $[33,34]$. Subjects underwent a $75 \mathrm{~g}$ oral glucose tolerance test and the insulinogenic index, an index of beta-cell function, was calculated as the increment in insulin at $30 \mathrm{~min}(\mathrm{pmol} / \mathrm{l})$ in relation to the increment in glucose at $30 \mathrm{~min}$ (pmol/1) [35].

Insulin was measured using an immunoenzymometric assay (Medgenix EASIA, Biosource, Nivelles, Belgium) calibrated against IRP 66/304 with no detectable cross-reactivity with intact proinsulin or 32,33 split proinsulin. Interassay coefficients of variation $(\mathrm{CV})$ were less than $10 \%$ over the range $95-1038$ $\mathrm{pmol} / 1$.

Genotyping. Four polymorphisms in the calpain-10 gene were typed as described by Evans and colleagues [19]. SNP-44 (CAPN10-g.4841T/C), SNP-43 (g.4852G/A), SNP-19 (g.7920indel32 bp) and SNP-63 (g.16378C/T). Alleles are numbered as previously described $[18,19]$.

Statistics. Data are presented as median (5 and 95 centiles). Comparisons between high and low risk genotypes (e.g. G/G v $\mathrm{G} / \mathrm{A}+\mathrm{A} / \mathrm{A}$ ) were made by Mann-Whitney U test. Comparisons between the three genotypes were made using Kruskal Wallis analysis of Variance.

\section{Results}

Homozygosity for SNP-43 allele 1 is associated with all haplotype combinations showing increased risk of diabetes in Mexican Americans as well as insulin resistance in the Pima Indians suggesting that this polymorphism has an important role in determining susceptibility to Type II diabetes. The subjects of this study were therefore first analysed for polymorphisms at this site. Twenty one subjects were homozygous for the G-allele (allele 1, genotype G/G) at SNP43, 12 where heterozygous (G/A) and four were homozygous for the A-allele (allele 2, genotype A/A). As the susceptibility is associated with homozygosity and CAPN10 mRNA is reduced in Pima Indians homozyous for the SNP-43G allele compared to individuals not homozygous for SNP-43 G-allele, we compared microvascular function in those with the G/G-genotype (Group 1) and a combined group of those with the G/A + A/A genotypes (Group 2). In addition the three genotypes were investigated separately.

No differences were observed between the G/G and $\mathrm{G} / \mathrm{A}+\mathrm{A} / \mathrm{A}$ genotype groups with regard to age, sex, weight, BMI waist-to-hip ratio, systolic or diastolic blood pressure, fasting plasma glucose or plasma glucose concentration $2 \mathrm{~h}$ after the $75 \mathrm{~g}$ oral glucose load, HOMA or insulinogenic index (Table 1).

Subjects with SNP-43 G/G-genotypes exhibited an increased $\mathrm{MMH}$ compared to those with $\mathrm{G} / \mathrm{A}+\mathrm{A} / \mathrm{A}$ genotypes $(1.6(0.95-2.28)$ v $1.4(0.78-1.72)$ volts, $p=0.011$ ), Fig. 1; MVR was correspondingly lower 49.4 (39.6-94.2) v 67.5 (39.1-107.3) $\mathrm{mmHg} / \mathrm{V}$, $p=0.007)$ Fig. 2 . When the three genotypes were analysed separately there was still a significant difference in both MMH ( $p=0.017)$ and MVR $(p=0.010)$.

Additional analysis of extended haplotypes (SNPs 43/44/16/63 including the at risk Caucasian haplotype described by Evans [19]) did not show significant results. The haplotype identified by Horikawa [18] as the highest risk combination for relative risk of diabe- 


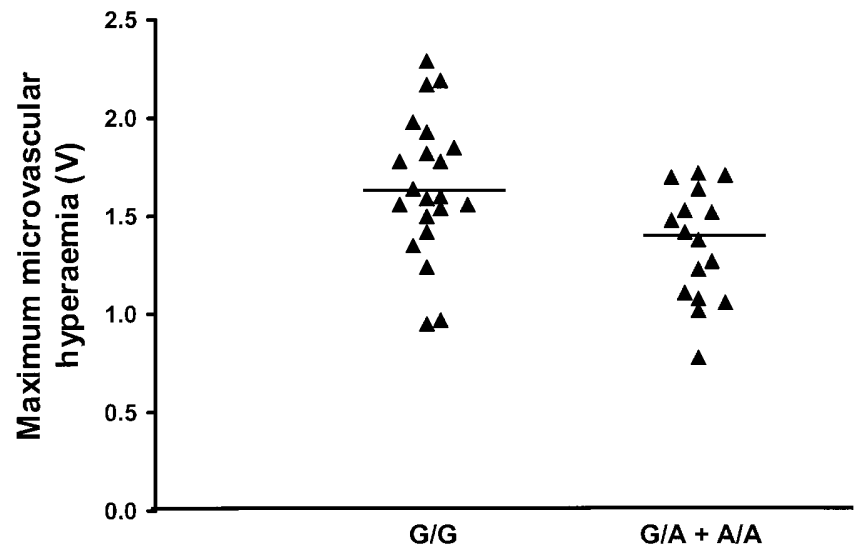

Fig. 1. Maximum microvascular hyperaemia $(\mathrm{MVH})$ based on SNP-43 genotype: G/G v G/A + A/A

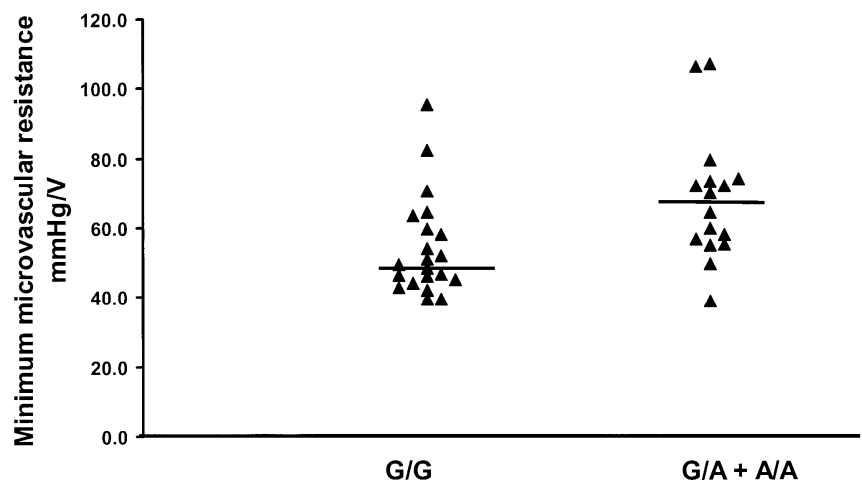

Fig. 2. Minimum microvascular resistance (mean systemic blood pressure/ maximum microvascular hyperaemia) (MMR) based on SNP-43 genotype: G/G v G/A+A/A

tes in the Mexican American 112/121 (SNPs $43 / 19 / 63$ ) occurred in only one of the 30 subjects with full haplotype data thus the effect of this haplotype on microvascular function is still not unknown.

\section{Discussion}

This study is the first demonstration that variation in a gene that predisposes certain populations to the development of Type II diabetes or insulin resistance is associated with altered microvascular function in healthy normoglycaemic Caucasian subjects. Interestingly homozygosity for SNP-43 allele 1 in this group appeared to confer an increased microvascular vasodilatory response rather than the depressed response commonly observed in those at risk of Type II diabetes. The explanation for the enhanced vasodilatation in this group is not clear but suggests the presence of an early hyperaemia which progresses to an impaired response as subtle abnormalities of the insulin resistant syndrome develop. The enhanced hyperaemia itself could contribute to the subsequent impairment in function $[36,37]$ through a delterious effect on the en- dothelium. The magnitude of the difference in the hyperaemic response between the two groups is modest being about half that seen when comparing controls and either fasting hyperglycaemic individuals or normoglycaemic individuals who have previously had gestational diabetes [38, 39].

The G-allele (allele 1) at SNP-43 is the only allele common to all the high-risk haplotypes seen in Mexican Americans suggesting that it either determines susceptibility to Type II diabetes or is the best marker of the true susceptibility allese(s). The SNP43 G allele or an allele in strong linkage disequilibrium (LD) with it appears to play a role in regulation of calpain expression. For example in vivo studies in Pima Indians demonstrate that G/G homozygotes have lower skeletal muscle CAPN10 mRNA and increased insulin resistance [20]. However studies in UK subjects did not find any association between Type II diabetes and SNPs 43, 19 and 63, either individually or as part of the previously described risk haplotypes or genotypes. Similarly alterations in vascular function were not associated with these extended haplotypes. In UK Caucasian non-diabetic subjects enriched with first-degree relatives of patients with Type II diabetes, investigators reported hyperglycaemia and beta-cell dysfunction associated with SNP-43 genotype [40]. In the current smaller study of individuals homozygous for the $\mathrm{G}$ allele in SNP-43, there was no evidence of increases in plasma glucose, indeed there was a trend for lower fasting glucose. This study did not, however, set out to assess effects of genotype on glucose metabolism and differences are likely to be explained by the small number of subjects studied.

This study was not designed to examine the mechanism responsible for the enhanced microvascular vasodilatory response observed in those homozygous for SNP-43 1 allele. MMH is a complex response involving neurogenic, endothelial dependent as well as structural determinants. Given the range of actions of the cysteine proteases it is quite conceivable that one or more of such determinants might be influenced by altered expression of Calpain 10.

In conclusion this study provides proof of principle that allelic variation in the intron region of the Calpain 10 gene could have consequences for microvascular function. The G allele of SNP43 that confers susceptibility to Type II diabetes in some populations is associated in UK Caucasians with enhanced microvascular hyperaemia in the presence of normoglycaemia.

Acknowledgements. This work was supported by The Wellcome Trust 032627/Z/96/, Diabetes UK, NHS Executive South and West R \& D Directorate Career Scientist Nov 98-Oct 03 CA/02/Frayling/98, U.S. Public Health Service Grants DK20595, DK-47486 and DK-55889 and the Howard Hughes Medical Institute. J. Evans was supported by an Exeter University Millhayes Scholarship. The University Hospital Birmingham Charities are thanked for their help. We are grateful to Dr. J. Levy for providing us with the HOMA programme. 


\section{References}

1. UK Prospective Diabetes Study 6 (1990) Complications in newly diagnosed type 2 diabetic patients and their association with different clinical and biochemical risk factors. Diabetes Res 13:1-11

2. The Diabetes Control and Complications Trial Research Group (1993) The effect of intensive treatment of diabetes on the development and progression of long-term complications in insulin-dependent diabetes mellitus. N Engl J Med 329:978-986

3. Jaap AJ, Tooke JE (1995) Pathophysiology of microvascular disease in non-insulin-dependent diabetes. Clin Sci (Colch) 89:3-12

4. Shore AC, Price KJ, Sandeman DD, Green EM, Tripp JH, Tooke JE (1991) Impaired microvascular hyperaemic response in children with diabetes mellitus. Diabet Med 8:619-623

5. Ewald U, Tuvemo T (1985) Reduced vascular reactivity in diabetic children and its relation to diabetic control. Acta Paediatr Scand 74:77-84

6. Jaap AJ, Hammersley MS, Shore AC, Tooke JE (1994) Reduced microvascular hyperaemia in subjects at risk of developing Type II (non-insulin-dependent) diabetes mellitus. Diabetologia 37:214-216

7. Caballero AE, Arora S, Saouaf R et al. (1999) Microvascular and macrovascular reactivity is reduced in subjects at risk for type 2 diabetes. Diabetes 48:1856-1862

8. Balletshofer BM, Rittig K, Enderle M et al. (2000) Endothelial dysfunction is detectable in young normotensive first-degree relatives of subjects with type 2 diabetes in association with insulin resistance. Circulation 101:1780-1784

9. Tooke JE, Goh K (1998) Endotheliopathy precedes Type 2 diabetes. Diabetes Care 21:2047-2049

10. Lee BC, Appleton M, Shore AC, Tooke JE, Hattersley AT (1999) Impaired maximum microvascular hyperaemia in patients with MODY 3 (hepatocyte nuclear factor-1 alpha gene mutations). Diabet Med 16:1-5

11. Arcaro G, Solini A, Monauni T et al. (2001) ACE genotype and endothelium-dependent vasodilation of conduit arteries and forearm microcirculation in humans. Arterioscler Thromb Vasc Biol 21:1313-1319

12. Butler R, Morris AD, Burchell B, Struthers AD (1999) DD angiotensin-converting enzyme gene polymorphism is associated with endothelial dysfunction in normal humans. Hypertension 33:1164-1168

13. Kurland L, Melhus H, Sarabi M, Millgard J, Ljunghall S, Lind L (2001) Polymorphisms in the renin-angiotensin system and endothelium-dependent vasodilation in normotensive subjects. Clin Physiol 21:343-349

14. van Dijk MA, Kroon I, Kamper AM, Boomsma F, Danser AH, Chang PC (2000) The angiotensin-converting enzyme gene polymorphism and responses to angiotensins and bradykinin in the human forearm. J Cardiovasc Pharmacol 35:484-490

15. Cockcroft JR, Gazis AG, Cross DJ et al. (2000) Beta(2)-adrenoceptor polymorphism determines vascular reactivity in humans. Hypertension 36:371-375

16. Hoit BD, Suresh DP, Craft L, Walsh RA, Liggett SB (2000) Beta2-adrenergic receptor polymorphisms at amino acid 16 differentially influence agonist-stimulated blood pressure and peripheral blood flow in normal individuals. Am Heart J 139:537-542

17. Schneider MP, Erdmann J, Delles C, Fleck E, RegitzZagrosek V, Schmieder RE (2000) Functional gene testing of the Glu298Asp polymorphism of the endothelial NO synthase. J Hypertens 18:1767-1773
18. Horikawa Y, Oda N, Cox NJ et al. (2000) Genetic variation in the gene encoding calpain-10 is associated with type 2 diabetes mellitus. Nat Genet 26:163-175

19. Evans JC, Frayling TM, Cassell PG et al. (2001) Studies of association between the gene for calpain-10 and type 2 diabetes mellitus in the United Kingdom. Am J Hum Genet 69:544-552

20. Baier LJ, Permana PA, Yang X et al. (2000) A calpain-10 gene polymorphism is associated with reduced muscle mRNA levels and insulin resistance. J Clin Invest 106: R69-R73

21. Patel YM, Lane MD (1999) Role of calpain in adipocyte differentiation. Proc Natl Acad Sci USA 96:12791284

22. Smith LK, Rice KM, Garner CW (1996) The insulin-induced down-regulation of IRS-1 in 3T3-L1 adipocytes is mediated by a calcium-dependent thiol protease. Mol Cell Endocrinol 122:81-92

23. Jaap AJ, Shore AC, Tooke JE (1997) Relationship of insulin resistance to microvascular dysfunction in subjects with fasting hyperglycaemia. Diabetologia. 40:238243

24. Vehkavaara S, Seppala-Lindroos A, Westerbaca J, Groop PH, Yki-Jarvinen H (1999) In vivo endothelial dysfunction characterises patients with impaired fasting glucose. Diabetes Care 22:2055-2060

25. Rattigan S, Clark MG, Barrett EJ (1997) Hemodynamic actions of insulin in rat skeletal muscle: evidence for capillary recruitment. Diabetes 46:1381-1388

26. Rattigan S, Clark MG, Barrett EJ (1999) Acute vasoconstriction-induced insulin resistance in rat muscle in vivo. Diabetes 48:564-569

27. Serne EH, Stehouwer CD, ter Maaten JC et al. (1999) Microvascular function relates to insulin sensitivity and blood pressure in normal subjects. Circulation 23:896902

28. Serne EH, Gans RO, ter Maaten JC, ter Wee PM, Donker AJ, Stehouwer CD (2001) Capillary recruitment is impaired in essential hypertension and relates to insulin's metabolic and vascular actions. Cardiovasc Res 49:161168

29. Fujitani K, Kambayashi J, Ariyoshi H et al. (1997) Calpain activation in shear-induced platelet aggregation. J Cell Biochem 66:54-64

30. Inomata M, Hayashi M, Ohno-Iwashita Y, Tsubuki S, Saido TC, Kawashima S (1996) Involvement of calpain in integrin-mediated signal transduction. Arch Biochem Biophys 328:129-134

31. Hong DH, Huan J, Ou BR et al. (1995) Protein kinase C isoforms in muscle cells and their regulation by phorbol ester and calpain. Biochim Biophys Acta 1267:45-54

32. Tanabe F, Cui SH, Ito M (1998) Ceramide promotes calpain-mediated proteolysis of protein kinase $\mathrm{C}$ beta in murine polymorphonuclear leukocytes. Biochem Biophys Res Commun 242:129-133

33. Matthews DR, Hosker JP, Rudenski AS, Naylor BA, Treacher DF, Turner RC (1985) Homeostasis model assessment: insulin resistance and B-cell function from fasting plasma glucose and insulin concentrations in man. Diabetologia 28:412-419

34. Levy JC, Matthews DR, Hermans MP (1998) Correct homeostasis model assessment (HOMA) evaluation uses the computer programme. Diabetes Care 21:21912192

35. Kosaka K, Kuzuya T, Hagura R, Yoshinaga H (1996) Insulin response to oral glucose load is consistently decreased in established mellitus: the usefulness of decreased early 
insulin response as a predictor of non-insulin-dependent diabetes mellitus. Diabet Med 13:S109-S119

36. Parving $\mathrm{H}-\mathrm{H}$, Viberti GC, Keen H, Christiansen JS, Lassen NA (1983) Hemodynamic factors in the genesis of diabetic microangiopathy. Metabolism 32:943-949

37. Tooke JE (1996) Microvasculature in diabetes. Cardiovasc Res 32:764-771

38. Jaap AJ, Hammersley MS, Shore AC, Tooke JE (1994) Reduced microvascular hyperaemia in subjects at risk of de- veloping Type II (non-insulin-dependent) diabetes mellitus. Diabetologia 37:214-216

39. Hannemann MM, Liddell WG, Shore AC, Clark PM, Tooke JE (2002) Vascular function in women with previous gestational diabetes mellitus. Vasc Res (In Press)

40. Lynn S, Evans JC, White C et al. (2002) Variation in the calpain-10 gene affects blood glucose levels in the British population. Diabetes 51:247-250 